Journal of Social and Development Sciences

Vol. 4, No. 6, pp. 286-293, June 2013 (ISSN 2221-1152)

\title{
Human Agency and Freedom at the Face of the Changing Global Environment
}

\author{
Manash Jyoti Deka \\ Indian Council for Philosophical Research \\ Jawaharlal Nehru University, New Delhi, India \\ jnu.manas@gmail.com
}

\begin{abstract}
The meteoric change of global environment in today's world can be understood at least in two contexts; symbolic and real, understanding it from the Lacanian point of view. The symbolic constructs a structure wherein human beings as subjects are subjectivized under a disguised hallucination of imagination. In addition, the real is that what the symbolic has lost in its very inauguration and therefore keeps desiring. When the symbolic comes to confront the real, i.e. when, for example, a global capitalistic structure faces a lurking nature which is now anti-posed against the symbolic itself due to its exploitive mentality of nature the subject becomes a paranoiac subject. Can a paranoiac subject exercise a real agency and thus recover her freedom without being a schizophrenic? In this paper, I want to discuss these issues from a psychoanalytic as well as philosophical point of view.
\end{abstract}

Keywords: Freud, Lacan, (Capitalistic) Symbolic-imaginary structure, Subject (ivization), Real Nature

\section{Introduction}

Let me start with the question of human agency? Oxford Dictionary of Critical Theory defines agency as "the degree to which a subject is able to determine the course of their own actions" ${ }^{1}$. Therefore, it is agency that saves the subject in a way from being a mere automaton. That is, a subject is a subject because she is an agent. However, a subject is also a subjectivized subject in the sense that she comes under the grip of hallucinatory imagination constructed by the ideology of culture. And, that is why human being can be called a subject, that she is a subject of a structure of the culture, for a subject cannot live alone; she must conform to the inter-subjective symbolic or language devised by the culture. ${ }^{2}$ The fact is what the symbolic or the language of the culture does is but to try to arrest the real of nature through the metaphoric expression of significance. ${ }^{3}$ This is the reason there must be the signifier that oscillates between the presence and absence before it is significantly captured by the imaginary of the inter-subjective - presence in the sense of the definite referent of sharable imagination in the symbolic-imaginary reality and absence in terms of indefinable and indefinite real against and beyond that very reality of the culture. That also establishes that the subject is split between the real and reality, or nature and culture, or signifier and signified, or unconscious or conscious, to speak of it from the Lacanian perspective of Freudian Psychoanalysis. Then, how can agency of the subject who is split be understood?

In fact, this splitness of the subject becomes prominent with the meteoric change of global environment. This change can be understood in the symbolic as well as the real as it can be thought at best by a finite human mind. How the symbolic has started, one can ask. It starts with the very inauguration of the social, the culture $^{4}$ For example, I would like to talk of exchanging of materials as it can be regarded as one of the bases of social beginning looking at the inter-subjective plan of the human society. Exchange in itself is a form, for it can be a gift or a symbol. In addition, what is exchanged is the content. The content may be anything as the form can differ. For example, we may surmise that Christianity started with an exchange in the name of a sacrifice. The history of human being reveals the fact that whatever can be considered as the most precious can be taken as the content of exchange. In this way, forms give rise to cultural taboos and norms. Thus, from the human being herself (remember the slavery in the West until recent times, or offering bribes or dowry in India, or offering the daughter of the defeated king to the victor king) to minute things anything could have been regarded as contents. At the present time, content has been associated with the process of contextualization and things have been crazy and complex comparing to the earlier age. The content becomes larger and stronger and it cannot fit to the form any more, for a form can remain a form only when human can 
control it in the present context. As for instance, money as content has become contentualized under a global system. When the process of exchange started in a mythical time ${ }^{5}$, contents could fit to the form, i.e. the exchange itself. Now contentualization becomes itself a form. How can a form fit itself to another form? Thus we require a process of formalization, may be in the name of politics or ethics.

I will call contentualization hallucinatory, because it covers the relative truths under a big carpet of structure insisting that only this structure can be the way of living a life. However, it is not the universal fact; it is just an effort in terms of a universalization that tries to substantialize contentualization in the name of a form as a surface ideological reality destroying the virtuality of other symbolic forms, which could also have been a way of living a life. For example, under the process of contentualization, the process of exchange itself was exchanged in terms of capitals or monetary system. This paves the way to further contentualizations as for instance, what is happening today is that that exchange of exchange is being exchanged again by something by a virtual space like internet. In addition, more this process of exchange is going on greater human is being reduced to something - something that is neither human nor non-human. Human being thus is becoming a taboo itself. Is it a fact city of being a human? In fact, contentualization can be compared to the process of signification of the signifier in which case a signifier can be taken as a form. In addition, why not, "(For) the signifier is a unique unit of being which, by its very nature, the symbol is of but an absence." And when any symbolic action once performed by human being itself turns out to devour her subjectivity, i.e. when a contentualization itself tries to determine what the formalization should be, in a way, if the signification tries to arrest the signifier; the form, the signifier revolts and tries to escape from the signification. In addition, "what remains of a signifier when it no longer has any signification ... (is) marked by blindness." 7 As Lacan says, "Such is the signifier's answer, beyond all significations: "You believe you are taking action when I am the one making you stir at the bidding of the bonds with which I weave your desires...that the signifier's answer to whomever questions it is: Eat your Dasein (i.e. being)."8

The global capitalism with its immanent strategy of using yet another artificial space reducing human being to mere subjectivized subjects is doing just only that, that by its inherent contentualization itself it is trying to determine what the formalization should be and this is the way human being has come to see the real of the nature once she imaginarily envisioned of capturing by the metaphoric substitution of the signifier. It is the global capitalistic structure that hankers after only profit and thus is incessantly exploiting the natural resources that indirectly offers human being the analytic cushion ${ }^{9}$ where something is going to "eat" her subjectivity, that, phenomenon like global warming or tsunami would eventually bring about sheer destruction. This unimaginable real is then only an effect of her cultural symbolic. The subject in fact is not bothered about the real at all.

Agency of human being, then, can be understood in retroaction done by the subject and in three ways -

- In the realization in an action performed by a subject who is subjectivized,

- In the realization in an acting out of a projected action by a subject who has already seen the predicament of her subjectivization, but committed to the Culture anyway.

- In the realization in an eventual Act ${ }^{10}$ done by a subject.

Coming to freedom. In accordance with the agency realized in three ways, freedom also can be thought of in three ways. For the first type freedom can be defined as the mediation between subjectivity and agency, as a subjectivized subject would like to think it to be. It is mediation in the sense that the subject thinks she gets a feeling of being an agent through it. However, in fact, it is only an imaginary freedom - a freedom that can seduce a subjectivized subject beyond measures. Therefore, we can say, actually, there is always a distance between agency and freedom in this case as the agent cannot recognize it due to the imaginary hallucination.

Thus the subject gradually gets subjectivized more and more in the network of cultural reality, thanks to language. The more she gets subjectivized the greater she loses her sense of real freedom that she could have achieved according to her own ontological nature. In place of real freedom she then develops the sense of an artificial imaginary-symbolic freedom and she thinks she has it when she speaks, thinks, or takes a decision. This is a trap because it is devised by the culture and being a subjectivized subject the subject has to internalize it in order to have a sense of freedom and agency. It - being with the superegoic ideal set by the culture - has to be internalized because only there is set the phenomenon of (artificial) 'human development'. 
Thus, this subject also keeps holding the status of being some agent somehow because only in this type of 'development' she runs the 'vehicle' of the culture. Therefore, the subject has no freedom in fact, though she may think she has it when she does something (which is, therefore, not doing but performing). Therefore, her agency which is based on an artificial freedom is hallucinatory from the philosophical point of view to comment on, and, thus she merely performs as a performer a role who (does not do anything herself but) is done under the dictation of the capitalistic cultural director.

Let me then reflect on the freedom that is realized in the second kind of agency. One of the exemplifications of this kind of agency can be found probably in the so-called middle class people in today's world of global capitalism. On the one hand, these people get that much of opportunity and success that they could also feel deprived of more benefits and pleasures that can always be imaginarily envisaged. In a way they feel deprived because they can reflect and they can reflect because they get something. Therefore these people's reflection occurs due to an objectified pleasure oriented formula devised by the society driven by the ideology of capitalism. On the other hand, they may also understand that they may be living in the end-time, as Zizek has argued, and thus they can think of staying out of this earth when they face a catastrophe like global warming, but they cannot find out a solution to the problem a universal capitalism may create - a problem which indirectly of course adds to the global warming. ${ }^{11}$ These people therefore becoming subjectivized always by the culture can only whimsically imagine of an alternative to the earth when they confront a real problem whereas cannot devise a symbolic substitution of the world they have prepared for themselves. To get rid of the paranoia in terms of real they can only escape from their responsibility and thus become paranoiac subjects. This subject then shits where she eats, and, thereby, she says that she cannot clean up this abject ${ }^{12}$ garbage. This happens to every kind of middle class subject - a middle class subject who suffers from the repose and leisure of being in the middle class and thereby deviated, and, she always tries to escape from this predicament although she can do it only by committing to this agency. As a consequence the subject becomes a paranoiac subject. She gets repose and leisure in the sense of the comfort she enjoys while sitting on the pendulous swing and doing nothing i.e. she thinks that she is driving her carrier and creating the momentum whereas she is in fact made to imagine like that by the repetitive formalization of the very swinging itself. We must understand, hence, that a middle class subject does not only contain the economic measurement, for she should be taken also as having socio-political, physico-psychological, ethno-cultural, or geographico-regional assessment. For example, a Freudian physico-psychological paranoiac oscillates between the measurement of unconscious and (pre)conscious and thus becomes a subject who struggles against these culturally devised theses in an effort of the recovery of subjectivity.

Alternatively, for example, a paranoiac subject may have an identity problem regarding the totem and taboo she is inclined to ethnically when and where an ideological cultural universalism in terms of a global citizenship is imposed on her own understanding of subjectivity. So, she finds herself in a situation where she cannot hold either to a relativistic position, for that does not support the investment of her traditional capital which is thoroughly rejected as a superstition or she has any other way to survival in a world where she has to fight back even for her prior existence she has lost under the cultural mask she is offered now when she wears. This is also the story of the Freudian paranoiac subject who in the search of her subjectivity eventually takes up an extreme position out of frustration ends up with a following of a contingent geography of the human subjectivity - a geography that has been forcefully drawn by her submission to a rationality whose method is only to objectify over a region of chaos where no mapping can actually be possible. That also advocates of an ideological pleasure in terms of a mask the subject wears that conceals any diabolical crime committed by her in a struggle of survival against any other outside of that very ideological identity, as she marks herself within a boundary by that mask separating her from what she in fact cannot cut herself off. However by committing to that kind of a crime the subject cannot remain calm without having a question as she does have the question being in a confrontation with the very relativism itself. That is why she has often to take recourse in an escapism in terms of a forgetfulness of responsibility. Her subjectivity dwindles between an oscillation of sudden reaction to any social activity, taking part in it with a relativistic attitude where freedom is set with a target from freedom from to freedom to, and, then forget the whole reaction in the lap of a formal action she is culturally subjectivized to in terms of a paranoia. In a way, she often resorts to nihilism that is why, with the frustration that remains (since it is a formality) despite her keen effort to recover from it. The mask of universalism under the influence of capitalistic ideology gets revealed here simply by the relativism but the very relativism also sustains its very nature of relativism qua relativism only 
because there could be an extreme universalism. It is but a simple formal trap, a paradoxical confrontation with life where the subject loses her true mission.

Thus she also becomes a socio-political victim who knows that she is being victimized; in order to save the society she looks forward to a political life which is in fact already set for her before her arrival and then thus in order to save the politics itself she becomes a vagabond in search of a true social commitment among her fellow beings. And in this job of symbolic itinerary the subject even loses her ethical dream once upon a time being influenced by the signifier and thus got purloined by the intersubjective game of group psychology ${ }^{13}$; and the subject gets stuck by the web between individualism and the group, or the ego and the cultural (super) ego and thereby unable to recognize that her subjectivity was apart from this (super) egoistic groupism or cultural conglomeration. As Freud has beautifully summarizes the predicament of the subject, "In him (the subject) when tension arises, it is only the aggressiveness of the superego which, in the form of reproaches, makes itself noisily heard; its actual demands often remain unconscious in the background. If we bring them to conscious knowledge, we find that they coincide with the precepts of the prevailing cultural super-ego. At this point the two processes that of the cultural development of the group and that of the cultural development of the individual, are, as it were, always interlocked. The cultural super-ego has developed its ideals and set up its demands. Among the latter, those, which deal with the relations of human beings to one another, are compromised under the heading of ethics. People have at all times set the greatest value on ethics (i.e. cultural morality); as though they expected that it in particular would produce especially important results. In addition, it does in fact deal with a subject, which can easily be recognized as the sorest spot in every civilization. Ethics is thus to be regarded as a therapeutic attempt - as an endeavour to achieve, by means of a command of the super-ego, something, which has so far not been achieved by means of any other cultural activities. As we already know, the problem before us is how to get rid of the greatest hindrance to civilization - namely, the constitutional inclination of human beings to be aggressive towards one another; and for that very reason we are especially interested in what is probably the most recent of the cultural commands of the super-ego, the commandment to love one's neighbor as oneself. In our research into, and therapy of, a neurosis, we are led to make two reproaches against the super-ego of the individual. In the severity of its commands and prohibitions it troubles itself too little about the happiness of the ego, in that it takes insufficient account of the resistances against obeying them - of the instinctual strength of the id [in the first place], and of the difficulties presented by the real external environment [in the second]." 14

A paranoiac subject thus herself gets entrapped of the vacillation between an inescapable predicament of objectification of subjectivization (from the third person perspective of cultural super-ego) and then subjectification (first person perspective of egoistic anxiety) of that objectification of human subjectivity. It is in the sense that, against the sublime transcendent Ethics that can do justice to nature, the subject at first metaphysically establishes cultural morality which can be called the objectification of subjectivization, as the subject objectifies her predicament in terms of values and taboos; and then she also subjectifies i.e. introjects in her subjectivity that very objectification. A paranoiac subject in fact must oscillate between subjectivization and subjectifica-tion (it is a tion - a formal institutionalization due to the imagination that revolves round the ego as the ego's imaginary, hence the subject cannot be said to have done it though she is responsible of the relationship she has with her ego), because she must perform the role of the analyzed (of the society) and commit at the same time to the (cultural) analyst (of the institution/ideology/signifier). Thus, she will be a victim of the endless process of (finding) freedom. Due to paranoia she suffers from, the subject must move from the one point to the other by trying to escape, and, thanks to narcissistic hallucination, she would remain performing an analyzed for a period of time being posed in a third person's role until and unless she gets verified and disposed of her contentualization, and, thanks to her previous home which is now occupied with new contents, she thus takes recourse back into the former formalization. She would be continuing this repetition automatism till she gets an opportunity in an eventual moment to look at herself and then come out of this kraal circle of culture.

Freedom, therefore, for this type of agency must be a metaphorical one. However, seeking freedom thus in a relativization via a formal structure is not a new story for the subject. In fact, the subject starts living it with the very inauguration of the subjectivity itself. We can understand it from the Freudian story of fort-da game. The subject replaces her Desire by a substitution and inaugurates a formal play upon the repression of her true nature and thereby feeling free in that metaphorical transformation of subjectivity. Therefore, freedom 
comes as the fort-da, as an oscillation, as a form, a normativity by which culture encroaches upon the subjectivity blocking or making unimportant with the help of repression the other possible ways of being rather than the cultural superegoic values or standardized norms. The question is, how can the subject get rid of this cultural fact city when even a primal scene can be interpreted as a metaphorical one, i.e. when even the first human cry can be considered as the first installing of the subject into a network of signifiers when and where the signifier saves as well as shapes the neonate's subjectivity from the sudden trauma of birth and hence of utmost helplessness with the metaphorical substitution of a cry. In fact, this is the primal metaphoric scene that paves the way for the subject as a lost subject in the future of a cultural temporality, talking of it from the point of a retroactive reflection a paranoiac subject can transcendentally deem. It also installs the subject in such a way in the cultural spatiality that the subject would find her identity hereafter only as posed; or disposed in accordance with the imposition of time, and, she comes out of a complete subjectivized status of hallucinatory agency if only she can find a repose during her continuous oscillation. This is the fact city that can be understood in terms of a paranoia always running after the subject and that propels her to continue her journey. The paranoiac subject is never satisfied due to this privation, for she can tell herself only that "I ran at par excellence but did not act anything" (Paranoiac: par-ran-no-I-ac $(\mathrm{t})$ ). Therefore, the paranoiac engages herself in a do or die situation, the death is possible only with the schizophrenic agency that tears apart the symbolic culture, this subject suffers from the paranoia tout court; she is afraid of dying in fact.

We can, thereby, also say that paradoxically this freedom is a means, not an end that looks for a permanent goal - a goal that can be achieved only by a schizophrenic agency in a no man's land when and where subjectivity can be recovered once again in its genuine form. In addition, the paranoiac subject would remain struggling with this confusion of a means or end; trying to decide again and again which one can be the proper way to freedom. This is a formal trap; and most of us, who are actually paranoiac subjects, struggle against this formality, may be, as for example, committing to an ideological motto what we think is a better symbolic than a previous oppressive one. Are we not becoming just paranoiac being afraid of the catastrophic global change? In fact, the real running through (the flesh and blood of) the subject surreptitiously always wants to stop this idealism - an idealism that palpably establishes itself in terms of a symbolc-maginary reality - an idealism where the subject oscillates between inferiority and superiority complex due to the paranoia she suffers from in respect with her effort to get a freedom from a freedom to. So, the fact is, this also means that the potential nature that all the time talks of a realism that tries to stop any quali-quantification of freedom, hence the culture; and, this indirectly provides a clue as if the subject gets an opportunity to be a real subject and thus be free somehow. The question is how the subject then would go for it? The question of 'how' can be realized in the fact that a real freedom which is realized in an Act of schizophrenic ${ }^{15}$ agency does not have any quali-quantification. It is beyond categories, thoughts, imagination, or objectification. It is both a-spatial and a-temporal from the point of the immanence. It is trans-spatio-temporal from the point of the transcendent. Hence though it can be said that there is a zone of real freedom where the subjectivity of the subject is fully recovered she in fact cannot either envisage or realize that she has got an opportunity until and unless she is under the supervision of cultural traits of measuring things with quali-quantification or spatio-temporality.

Moreover, there is no distance to it from the agency since having It means the recovery of the subjectivity and executing the agency altogether. Therefore, the question of any 'how', in fact does not arise here. Because, from the cultural point of view it is an impossible and unthinkable zone even if the subject could ever achieve it. However, however, still It is there, theoretically speaking, that makes the subject a real subject, for on the very ground against It only the formula of a paranoiac freedom and agency can be envisaged. It is there because there cannot only be idealism but there must also be realism that saves the subject from the universal reverie of the culture. It is, to speak of it then within the periphery of a cultural language, the unthinkable or the unimaginable in the sense that it is either too simple or too complex to be thought of under the cultural categorization. Therefore, it just occurs as it must be there in the subjectivity. It brings in or evokes a zone in the subject, which is neither human nor non-human, but simply a-human, which in any case does not mean to be a cultural category of anti-human. It makes a subject singular in the truest sense in terms of the furthest possible imagination the culture may have, in the sense that it is neither cultural nor natural, neither bound by a (super)egoic (pre)conscious nor any unconscious id. So, subjectivity is celebrated in its fullest form, say, to gauge it in a maximum possible way of expression within the culture as it can be thought by a paranoiac subject in her schizophrenic meditation of the real nature. And thus it can also be easily 
understood how a subject entrapped by the cultural seduction would suffer paranoiac agency, understood in a defenseless manner but not any longer paralyzed ${ }^{16}$ because it is after all an agency, in three ways of her committed actions in search of freedom - a freedom Freud himself was looking for as a paranoiac subject when the subject would always require a symbolic god in a fatherly manner i.e. in the style of a task the (super) egoic (pre)conscious of the culture devises - by exorcising the terrors of nature (real real), by reconciling to the cruelty of fate in terms of death (imaginary real), and by compensating for the sufferings and privations which a civilized life in common imposes on the subject (symbolic real). ${ }^{17}$

The ontology where nature breathes, where other creatures as well as non creatures live beyond the anthropocentric imagination of culture cannot be captured by a freedom capitalistic imagination may indirectly advocate to. In a way, this kind of theory does not advocate of a freedom of a human subject in terms of the capacity of rationality to comment on and capture the human fact city. However, it, then, remains only at the level of thought - the thought what seeks to rationalize feelings or intuitions. In fact, it can easily be argued that once the subject acquires the necessary development to adjust with the pressure of both nature and culture she can be free. Sublimity or a real freedom is always transcendent, a surplus beyond subjectivization. In addition to this, the paranoiac nature of human subjectivized predicament will always make the subject suffer from or toil over ways of living that get changed again and again under the influence of objectification in search of such a kind of objectified freedom that ironically enough can be found only in a ridiculous balance. Can the human subject who must oscillate between hallucination and paranoia under the fact city of subjectivization ever be balanced to be free being within that very subjectivizaion? That is also the reason that even though a subject takes up an a-humanistic stance being within the condition of subjectivization it cannot be summed up that she could achieve freedom as such as that stance is out of frustration, for it may turn out to be actually not a-humanistic but de-humanistic. She, the subject taking recourse in this stance, therefore, cannot ever be joyful in a real sense, for she can only resort to an escapism fleeing away from her responsibility by committing to that. In search of 'development' of civilization, then, this subject only resorts to a de-eve-(of)-elopement, that is, at the adjoining point of her continuous oscillation between day and night where the subject could have found out her subjectivity, at the moment of discovering the singularity of subjectivity in an evening the subject puts on a de to distort her decision of taking up responsibility. Therefore, a maintenance of balance and thereby freedom of a middle way under the influence of symbolic gets deviated. And, thus, the subject remains sunk in an ignorance paying a deaf ear to her greatest responsibility to come to her true being, to be her own self, or to recover her subjectivity and thereby freedom from her own subjectification first.

Coming back to the subject, the subject becomes somebody like a lover of forbidden love when she achieves the aesthetic mode (of accident, of intermingling that what cannot be normally intermingled). From a mundane symbolic point of view, a lover who loves another of what the culture cannot permit is recognized as made and therefore schizophrenic by the inter-subjective point of judgment. However, exercising that impossibility the lover spreads the dangerous message that anybody can (be in) love. In addition, this fact that anybody can be in love with anybody cannot be entertained by the normativity of the capitalistic culture. By her eventual act of executing love the subject of course gives a shock to the symbolic and teaches an ethics to the inter-subjective world - an ethics which is repressed by the culture under the veil of superficial morality which can easily be politicized by the hegemonic seduction of hallucinatory ideology.

\section{Does the capitalistic culture offer any opportunities to the subject to be a real agent?}

So far a subject of paranoiac agency can envisage being in a position to say something of it, I want to say that it can be categorized at least in three ways. There may be a point where two contradictory currents of the culture meet each other. Often ambushes and chaos occur due to this type of confrontation. Though this contradiction happens to be symbolic-imaginary, the consequence this clash leaves behind is a real one. Then, there arises an opportunity of making a boundary - and a no man's land thus also usurps. The subject in that place can see both the currents from a proper distance in an appropriate time. For example, we can think of the ethnic clash with capitalism where the subject can rediscover herself out of a loss of falling between a superstitious native normativity and a seductive modern leisure and comfort as soon as she feels that she can belong to neither of them. There may be another point where the superficiality of culture gets exposed due to the competition two contrary cultural trends set for themselves. If the first one, i.e. the contradiction is inter- 
cultural clash then this one is an intra-cultural problem when and where the subject gets a tans-cultural transcendent vision. For example, we can think of the clash between the Hindus and the Muslims or any identity struggles between a tribe and a mainstream identity. Politicization in terms of ideological differences plays a major role in this type of clashes and the subject gets opportunities to become a political subject here. The fact is that these contrary cultural trends can very well co-exist if not influenced by the former contradictory one.

There is another bigger clash. The culture itself confronts the nature. It happens when the culture either directly encounters the natural Nakedness face to face or, indirectly, tries to imitate the nature or creates a kind of virtual nature running parallel to the real nature, which threatens the nature in some way around. This clash is understood by the subject when and where she finds a cultural abutment beyond the cultural anthropocentricism. In addition, when we are talking of a real meteoric global change we are discussing nothing but only this. The first one comes to the subject as a symbolic real, the second one gets along as an imaginary real, and, the third happens as the real. In fact, these intra-cultural clashes, or inter-culturalconflicts, or the trans-cultural-combat whatever are possible to be delineated in a rational understanding in terms of the three hegemonic universals Zizek talks of apropos of the Lacanian order of imaginary, symbolic, and real respectively. The subject standing in the subjective stand of polar particularity against the universality of these hegemonic forces can get the opportunity of being a singular subject through these battles. The subject can use these opportunities without losing her subject-hood because as the universal they can in fact always be relativized in the imaginary of the subject in a way. However, a universal can hold the status of the universal if it is celebrated as such in a plane of inter-subjectivity. In Freudian way to talk of it, universals are universals because they are fetish for the subject and shared as a taboo, for only then they can be predicated to many particulars at the same time when they earn a sacred symbolic place in the subject's imagination. And this is the way the 'impasses' that demonstrate how the complex structure of the universal is created should also be understood - that 'the 'real' universality of globalization' is confronting the nature in an combative encounter, 'the universality of the fiction that regulates ideological hegemony is conflicting with another hegemonic current of ideology' (as for example Church and State got into a contrary conflict during a period of enlightenment), or 'the universality of an Ideal, as exemplified by the revolutionary demand for egaliberte' (personified in a Freudian image of a boyfriend or girlfriend as revealed in the era of hallucinatory feminism that re-establishes patriarchy masochistically in a paradoxical manner) is battling in an intra-cultural clash (as revealed in the event of honor-killing, or, anti-caste marriage, etc. in India). ${ }^{18}$ It is up to the subject then whether she would be a lover, a schizophrenic to search for an alternative symbolic that can account for the love the (M) other of real nature still keeps for us.

\section{References}

Buchanan, I. (2010). A Dictionary of Critical Theory. Oxford, New York: Oxford University Press.

Deleuze, G. \& Guattari, F. (2005). Anti-Oedipus: Capitalism and Schizophrenia. London and New York: Continuum.

Freud, S. (2003). On Metapsychology: The Theory of Psychoanalysis. New Delhi: Shrijee's Book International. Freud, S. (2003). Civilization, Society and Religion, Book No. 12. New Delhi: Shrijee's Book International.

Heidegger, M. (2012). Basic Writings: Special Indian Edition. London and New York: Routledge.

Lacan, J. (2006). Ecrits: The First Complete Edition in English. Trans. By Bruce Fink. New York and London: W. W. Norton \& Company.

Zizek, S. (2007). The Ticklish Subject, the Absent Centre of Political Ontology. New Delhi: ABS Publishers \& Distributors.

Zizek, S. (2010). Living in the End Times. London: Verso.

\section{Endnotes:}

${ }^{1}$ Buchanan, I. (2010). A Dictionary of Critical Theory. Oxford, New York: Oxford University Press. pp. 10-11.

${ }^{2}$ See Lacan, J. (2006). Ecrits: The First Complete Edition in English. Trans. By Bruce Fink. New York and London: W. W. Norton \& Company. pp. 11-46. 
3 See Ibid. pp. 189-268, and, 671-700.

${ }^{4}$ According to Lacan it is a corruption against the unity of nature. See Ibid. pp. 58-76.

5 When the human culture just started.

${ }^{6}$ Lacan, J. (2006). Ecrits: The First Complete Edition in English. Trans. By Bruce Fink. New York and London: W. W. Norton \& Company. p.17.

7 Ibid, p.28

8 Ibid. p.29

${ }^{9}$ An analytic cushion is the place where the subject lies down, reclines and vomits signifiers in accordance to the instruction given to him by the analyst. Many a time, therefore, a serious mistake is committed, that the analyst himself imposes his thoughts upon the subject's unconscious and the subject tries to imagine that as if it is actually her memories. See Ibid. pp.197-268.

10 Act is a noun and at the same time a verb. We can say that this is the indecisiveness, the impossibility the Culture cannot capture of an Act, that Act is as a noun static, signified, metaphysical, imaginary but as a verb dynamic, signifier(Ed), ontological, symbolic.

11 Zizek, S. (2010). Living in the End Times. London: Verso. p. 10.

12 "That which disturbs the self, by provoking either disgust, fear, loathing or repulsion. Belonging to the realm of the psychic, the abject is the excessive dimension of either a subject or an object that cannot be assimilated. As such, it is simultaneously outside or beyond the subject and inside and of the subject. Our own bodily fluids are for the most part loathsome to us, but the intensity of that loathing owes precisely to the fact that they come from us. Thus human faces are more disgusting to us than dog faces, despite the fact that there is no real difference between them."

Buchanan, I. (2010). Dictionary of Critical Theory. Oxford, New York: Oxford University Press. p.1.

13 Lacan, J. (2006). Ecrits: The First Complete Edition in English. Trans. By Bruce Fink. New York and London: W. W. Norton \& Company. pp. 20-21.

14 Freud, S. (2003). Civilization, Society and Religion, Book No. 12. New Delhi: Shrijee's Book International. pp. 353-354.

${ }^{15}$ I am taking schizophrenia in the Deleuzian sense of schizoanalysis. See Deleuze, G. and Guattari, F. (2005). Anti-Oedipus: Capitalism and Schizophrenia. London and New York: Continuum.

16 "...(I)f everywhere in nature there are Beings around us of a kind that we know in our own society, then we can breathe freely, can feel at home in the uncanny and can deal by psychical means with our senseless anxiety. We are still defenseless, perhaps, but we are no longer helplessly paralyzed; we can at least react."

Freud, S. (2003). Civilization, Society and Religion, Book No.12. New Delhi: Shrijee's Book International. p.204.

17 “... (B) ut he (the subject) gives them the character of a father. He turns them into gods, In the course of time the first observations were made of regularity and conformity to law in natural phenomena, and with this, the forces of nature lost their human traits. However, man's helplessness remains and along with it his longing for his father, and the gods. The gods retain their threefold task: they must exorcize the terrors of nature, they must reconcile men to the cruelty of Fate, particularly as it is shown in death, and they must compensate them for the sufferings and privations which a civilized life in common has imposed on them."

Freud, S. (2003). Civilization, Society and Religion, Book No.12. New Delhi: Shrijee's Book International. p.205.

18 Zizek, S. (2007). The Ticklish Subject, The Absent Centre of Political Ontology. New Delhi: ABS Publishers \& Distributors. P.213 